\title{
Vacinas de mRNA contra a Covid-19: aberta uma nova janela no campo da imunologia
}

\author{
Covid-19 mRNA vaccines: a new window opens in the field of immunology \\ Vacunas de ARNm de Covid-19: se abre una nueva ventana en el campo de la inmunología
}

Bárbara Queiroz de Figueiredo ORCID: https://orcid.org/0000-0003-1630-4597 Centro Universitário de Patos de Minas, Brasil

E-mail: barbarafigueiredo@unipam.edu.br Antônio Ricardo Neto ORCID: https://orcid.org/0000-0001-6647-9374 Centro Universitário de Patos de Minas, Brasil E-mail: antonioneto12@unipam.edu.br

Bruno Faria Coury

ORCID: https://orcid.org/0000-0002-9236-8552 Centro Universitário de Patos de Minas, Brasil

E-mail: brunofaria@unipam.edu.br

Clarisse Queiroz Lima de Araújo ORCID: https://orcid.org/0000-0001-6202-7530 Centro Universitário de Patos de Minas, Brasil E-mail: clarisselima@unipam.edu.br Júlia de Mendonça Queiroz ORCID: https://orcid.org/0000-0002-5856-3901 Centro Universitário de Patos de Minas, Brasil

E-mail: juliamendoncaqueiroz@gmail.com

Kerolyn Keshyley de Sousa

ORCID: https://orcid.org/0000-0002-4508-8718 Centro Universitário de Brasília, Brasil

E-mail: kerolynks@hotmail.com

Laila Caroline Silva Sousa

ORCID: https://orcid.org/0000-0002-9632-8208 Centro Universitário de Patos de Minas, Brasil E-mail: lailacarolline23@hotmail.com

Lorena Martins Servulo de Sousa ORCID: https://orcid.org/0000-0003-2643-8628 Centro Universitário Uninovafapi, Brasil

E-mail: lorenamartinservulo@gmail.com

Luan Ferreira Caixeta

ORCID: https://orcid.org/0000-0003-4620-524X Centro Universitário de Patos de Minas, Brasil E-mail: luan.fcaixeta@hotmail.com Luana Silva Cyrino

ORCID: https://orcid.org/0000-0002-7949-3607 Centro Universitário de Atenas, Brasil E-mail: luanasilvacyrino@outlook.com

Maria Luísa Alves Peres

ORCID: https://orcid.org/0000-0002-5528-6478 Centro Universitário de Patos de Minas, Brasil E-mail: marialuisa1@unipam.edu.br

Sarah Rabelo Fernandes

ORCID: https://orcid.org/0000-0003-0409-4772

Centro Universitário de Patos de Minas, Brasil E-mail: sarahrabelo@unipam.edu.br

\section{Resumo}

Introdução: A tecnologia de RNA mensageiro (mRNA) é uma plataforma investigada há muitos anos. A emergência da pandemia da Covid-19 obrigou que cientistas de todo o mundo se unissem em torno do desenvolvimento de diversas vacinas, tendo apostado naquelas que são tidas como convencionais, ou seja, com base no vírus propriamente dito, mas inativado, ou em seus fragmentos, cultivando-os em laboratório. Objetivo: Evidenciar o mecanismo de ação das vacinas mRNA contra a Covid-19. Metodologia: Trata-se de uma pesquisa descritiva do tipo revisão integrativa da literatura, que busca evidências sobre as vacinas mRNA contra a Covid-19. A pesquisa foi realizada por meio de 
bases de dados PubMed, MEDLINE, Scielo, CDSR, Google Scholar, BVS e EBSCO, no período de 2015 a 2021. Resultados: A abordagem do RNA é um fato bastante interessante e importante, pois esses RNAs, idênticos aos virais, são introduzidos dentro das células do sistema imune do corpo humano, induzindo-as a produzirem partes de uma proteína que o vírus também fabrica, chamada spike $(\mathrm{S})$, facilmente identificada através de cada uma das pontas que já se conhece nas imagens do vírus da Covid-19. Conclusão: Este é apenas o início de uma grande revolução tecnológica para a produção de vacinas que poderão, no futuro, combater diversos outros vírus usando essa tecnologia com segmentos de mRNA diferentes, propiciando o desenvolvimento de tratamentos para várias doenças através do mesmo princípio de ação.

Palavras-chave: Covid-19; Vacinas; mRNA; Antígenos; Proteína spike.

\begin{abstract}
Introduction: Messenger RNA (mRNA) technology is a platform that has been investigated for many years. The emergence of the Covid-19 pandemic forced scientists from all over the world to unite around the development of several vaccines, having bet on those that are considered conventional, that is, based on the virus itself, but inactivated, or on its fragments, cultivating them in the laboratory. Objective: To demonstrate the mechanism of action of mRNA vaccines against Covid-19. Methodology: This is a descriptive research of the integrative literature review type, which seeks evidence on mRNA vaccines against Covid-19. The search was conducted using PubMed, MEDLINE, Scielo, CDSR, Google Scholar, BVS and EBSCO databases, from 2015 to 2021. Results: The ANN approach is a very interesting and important fact, because these ANNs, identical to viral, are introduced into the cells of the human body's immune system, inducing them to produce parts of a protein that the virus also manufactures, called spike (S), easily identified through each of the tips that are already known in the Covid-19 virus images. Conclusion: This is just the beginning of a great technological revolution for the production of vaccines that may, in the future, fight several other viruses using this technology with different mRNA segments, providing the development of treatments for various diseases through the same principle of action.
\end{abstract}

Keywords: Covid-19; Vaccines; mRNA; Antigens; Spike protein.

\title{
Resumen
}

Introducción: La tecnología Messenger RNA (mRNA) es una plataforma que se ha investigado durante muchos años. La aparición de la pandemia Covid-19 obligó a científicos de todo el mundo a unirse en torno al desarrollo de varias vacunas, habiendo apostado por las que se consideran convencionales, es decir, basadas en el propio virus, pero inactivado, o en sus fragmentos, cultivarlos en el laboratorio. Objetivo: Demostrar el mecanismo de acción de las vacunas de ARNm contra Covid-19. Metodología: Se trata de una investigación descriptiva del tipo revisión integradora de la literatura, que busca evidencia sobre vacunas de ARNm contra Covid-19. La búsqueda se realizó utilizando las bases de datos PubMed, MEDLINE, Scielo, CDSR, Google Scholar, BVS y EBSCO, de 2015 a 2021. Resultados: El enfoque de las RNA es un dato muy interesante e importante, porque estas RNA, idénticas a las virales, se introducen en las células del sistema inmunológico del cuerpo humano, induciéndolas a producir partes de una proteína que también fabrica el virus, llamada pico $(\mathrm{S})$, que se identifica fácilmente a través de cada una de las puntas que ya se conocen en las imágenes del virus Covid-19. Conclusión: Este es solo el comienzo de una gran revolución tecnológica para la producción de vacunas que puedan, en el futuro, combatir varios otros virus utilizando esta tecnología con diferentes segmentos de ARNm, proporcionando el desarrollo de tratamientos para diversas enfermedades a través del mismo principio de acción.

Palabras clave: Covid-19; Vacunas; ARNm; Antígenos; Proteína de pico.

\section{Introdução}

O coronavírus SARS-2 (SARS-CoV-2), que surgiu como um surto na província de Hubei, na China, agora se espalhou rapidamente para muitas partes do mundo, causando uma pandemia. A infecção com SARS-CoV-2 resulta em uma doença pulmonar, chamada Covid-19, que está provando ser um grande problema de saúde global. Proporção substancial de casos progride para doença grave, onde aproximadamente $5 \%$ dos pacientes requerem suporte de terapia intensiva e mais de $20 \%$ dos casos críticos sucumbem à doença. Embora a taxa de mortalidade geral seja provavelmente menor do que as estimativas atuais, como a prevalência de casos levemente sintomáticos ainda não foi claramente definida, a Covid-19, no entanto, representa uma emergência de saúde global (Alwis et al., 2020).

A tecnologia de RNA mensageiro (mRNA) é uma plataforma investigada há muitos anos. A emergência da pandemia da Covid-19 obrigou que cientistas de todo o mundo se unissem em torno do desenvolvimento de diversas vacinas, tendo apostado naquelas que são tidas como convencionais, ou seja, com base no vírus propriamente dito, mas inativado, ou em seus fragmentos, cultivando-os em laboratório. Assim, a janela da ciência se escancarou quando foi apresentada a proposta de 
desenvolver vacinas de RNA contra a Covid-19, ou seja, produzidas em laboratório. A abordagem do RNA é um fato bastante interessante e importante, pois as cópias idênticas dos RNAs, idênticos aos virais, são introduzidos dentro das células do sistema imune do corpo humano, induzindo-as a produzirem partes de uma proteína que o vírus também fabrica, chamada spike (S), facilmente identificada através de cada uma das pontas que já se conhece nas imagens do vírus da Covid19. Por ser muito instável, o mRNA é recoberto por uma capa de lipídios que o protegerá. É essencial ressaltar que a molécula não contém outra informação, ou seja, não é capaz de realizar qualquer outra tarefa, e, sendo assim, penetra ao núcleo das células humanas (Jackson, et al., 2020).

Uma vez que o conteúdo da vacina é injetado e capturado pelas células apresentadoras de antígeno, a partir das instruções do mRNA são fabricadas as proteínas "S" do novo coronavírus que, então, são transportadas até a superfície da célula, onde os processos de defesa são desencadeados. Os linfócitos $\mathrm{T}$ auxiliares detectam a proteína estranha e recrutam os linfócitos B, responsáveis pela produção de anticorpos; os linfócitos B entram em contato com a proteína "S" da superfície e produzem os anticorpos específicos contra ela, que neutralizarão o novo coronavírus; outras células de defesa chamadas linfócitos $\mathrm{T}$ citotóxicos reconhecem e destroem diretamente qualquer estrutura que exiba a proteína "S" em sua superfície; quando a célula que absorveu o mRNA sofre apoptose, a proteína "S" e seus fragmentos liberados podem ser identificados pelo sistema humano de defesa que também desencadeia todo o processo (Lurie, et al. 2020).

\section{Metodologia}

Trata-se de uma pesquisa descritiva do tipo revisão integrativa da literatura, que buscou evidenciar o mecanismo de ação das vacinas mRNA contra a Covid-19. A pesquisa foi realizada através do acesso online nas bases de dados National Library of Medicine (PubMed MEDLINE), Scientific Electronic Library Online (Scielo), Cochrane Database of Systematic Reviews (CDSR), Google Scholar, Biblioteca Virtual em Saúde (BVS) e EBSCO Information Services, nos meses de junho e julho de 2021. Para a busca das obras foram utilizadas as palavras-chaves presentes nos descritores em Ciências da Saúde (DeCS): em inglês: "vaccine", "RNA", "spike protein", "Covid-19", "antigen presenting cells", "antibodies", em português "vacina", "RNA", "proteína spike", "Covid-19", "células apresentadoras de antígenos", "anticorpos", e em espanhol: "vacuna", "ARN", "proteína de pico", "Covid-19", "células presentadoras de antígeno", "anticuerpos".

Como critérios de inclusão, foram considerados artigos originais, que abordassem o tema pesquisado e permitissem acesso integral ao conteúdo do estudo, publicados no período de 2015 a 2021, em inglês, português e espanhol. O critério de exclusão foi imposto naqueles trabalhos que não estavam em inglês, português ou espanhol, que não tinham passado por processo de Peer-View e que não abordassem as vacinas mRA. A estratégia de seleção dos artigos seguiu as seguintes etapas: busca nas bases de dados selecionadas; leitura dos títulos de todos os artigos encontrados e exclusão daqueles que não abordavam o assunto; leitura crítica dos resumos dos artigos e leitura na íntegra dos artigos selecionados nas etapas anteriores. Assim, totalizaram-se 22 artigos científicos para a revisão integrativa da literatura, com os descritores apresentados acima. Após esta seleção, filtraram-se por artigos dos últimos seis anos e por artigos em línguas portuguesa, inglesa e espanhola.

\section{Resultados e Discussão}

A Covid-19 é uma doença infecciosa emergente que se tornou uma pandemia. Ele se espalha através da transmissão de gotículas do novo coronavírus SARS-CoV-2. É um vírus de RNA exibindo uma proteína de pico como a principal proteína de superfície com similaridade de sequência significativa com o SARS-CoV que causa a síndrome respiratória aguda grave. O domínio de ligação ao receptor da proteína spike interage com a enzima conversora de angiotensina humana 2 e é considerado o determinante antigênico para estimular uma resposta imune. Seu genoma de RNA de fita positiva consiste em seis principais quadros de leitura aberta e genes acessórios que codificam as proteínas não estruturais típicas, incluindo a RNA polimerase 
dependente de RNA, proteases e as proteínas estruturais, incluindo a matriz, envelope, pico e nucleoproteína. A glicoproteína de pico de superfície é responsável pela ligação ao receptor da superfície da célula humana, seguida pela fusão e entrada na membrana, fundamental para determinar a especificidade do hospedeiro, estimar a capacidade de transmissão de doenças e para a produção de anticorpos neutralizantes em humanos. Geralmente, a proteína spike dos coronavírus consiste em um peptídeo sinal, regiões extracelulares, transmembranares e intracelulares (Mukherjee, 2020).

A tecnologia de vacinas evoluiu significativamente na última década, incluindo o desenvolvimento de vários candidatos a vacinas de RNA e DNA, vacinas vetoriais licenciadas (por exemplo, Ervebo, uma vacina de ebolavírus com vetor de estomatite vesicular [VSV], licenciada na União Europeia), proteína recombinante vacinas (por exemplo, Flublok, uma vacina contra o vírus da gripe produzida em células de insetos, licenciada nos Estados Unidos) e vacinas baseadas em cultura de células (por exemplo, Flucelvax, uma vacina contra o vírus da gripe produzida em células de mamíferos). O SARS-CoV-2 foi identificado em tempo recorde e sua sequência genômica foi rapidamente disponibilizada amplamente por pesquisadores chineses. Além disso, sabe-se da existência de estudos sobre SARS-CoV-1 e as vacinas MERS-CoV relacionadas que a proteína $S$ na superfície do vírus é um alvo ideal para uma vacina (Amanat et al. 2020).

Em circunstâncias normais, o desenvolvimento de uma vacina levaria anos para ir do conceito aos testes clínicos. No entanto, as lições da pesquisa sobre o SARS-CoV e o MERS-CoV relacionados permitiram o desenho rápido de candidatos à vacina SARS-CoV-2, em 2020, para desenvolvimento clínico. Alternativamente, o Food and Drug Administration (FDA) observou que poderia implementar uma Autorização de Uso de Emergência (EUA) para disponibilizar uma vacina COVID-19 antes mesmo de sua avaliação completa ser concluída. (Avorn, et al. 2020). As estratégias de vacinação tradicionais são as seguintes: as que usam uma versão atenuada do agente infeccioso; as que recorrem ao agente infeccioso inativado; as que introduzem no organismo um componente do patógeno, uma proteína do vírus; e as que administram toxinas produzidas pelo agente infeccioso. Algumas das atuais vacinas contra o SARS-Cov-2 são as primeiras à base de DNA ou de RNA a ser aprovadas para uso humano (Barreto, et al., 2021). Em comparação com outros vírus de RNA, o coronavírus tem uma maquinaria molecular mais complexa, resultando em maior fidelidade de replicação (Dearlove et al., 2020).

Essas vacinas têm um objetivo comum, ou seja, induzir respostas de anticorpos policlonais contra a proteína spike do SARS-CoV-2 para neutralizar a infecção viral. As vacinas candidatas abrangem uma grande diversidade de plataformas de vacinas, incluindo mRNA, DNA, nanopartículas, subunidades e vetores virais. Algumas das novas plataformas tecnológicas, como vacinas de DNA e mRNA, podem teoricamente permitir que milhões de doses de vacina sejam fabricadas rapidamente em meses e implantadas em regiões de necessidade (Alwis et al., 2020). O uso de RNA mensageiro como vacina é uma estratégia relativamente nova, e nenhuma vacina licenciada ainda utilizou esse método. O conceito é simples: injetar a codificação do mRNA para a proteína spike e deixe o hospedeiro produzir a proteína. Uma vantagem dessa abordagem é uma rota razoavelmente direta para a manufatura, permitindo o rápido aumento da produção (Caddy, 2020).

Semelhante às vacinas de DNA, as vacinas de RNA contêm informações genéticas selecionados do vírus na forma de mRNA e, após a entrega citosólica, esses genes são traduzidos em proteínas virais. O mRNA-1273 da Moderna Therapeutics (Cambridge, MA, EUA) é a primeira vacina candidata que entrou em testes clínicos de fase 1 apenas 42 dias após o sequenciamento completo do genoma SARS-CoV-2 (Frederiksen et al. 2020). Nesse sentido, o mRNA-1273 é uma vacina baseada em mRNA encapsulada em nanopartículas lipídicas (LNP) que codificam a proteína S estabilizada de pré-fusão de comprimento total de SARS-CoV-2. Esta plataforma de tecnologia baseada em LNP foi anteriormente mostrada por induzir fortes respostas imunológicas e proteção contra uma série de patógenos diferentes em estudos pré-clínicos (Espeseth et al., 2020). O perfil de imunogenicidade rápido e robusto da vacina de mRNA-1273 provavelmente resulta de um projeto inovador de antígeno de vacina baseado em estrutura, acoplado a um potente sistema de entrega de nanopartículas de lipídios e o uso de nucleotídeos modificados que evitam a ativação intracelular precoce de interferons associados. Estas características da 
composição e formulação do mRNA foram associadas à expressão prolongada de proteínas, indução de células auxiliares foliculares T específicas do antígeno e ativação de células B do centro germinativo (Jackson, et al., 2020).

Já o programa candidato a vacina baseada em mRNA BNT162 da BioNTech's (Mainz, Alemanha), que é desenvolvido em conjunto com a Pfizer, é baseado na vasta experiência da BioNTech no desenvolvimento de terapêuticas baseadas em mRNA, em particular contra o câncer, usando moléculas de mRNA personalizadas e sistemas de entrega intracelular (Stalder et al., 2017). O BNT162 compreende quatro vacinas candidatas, cada uma das quais representa diferentes formatos de mRNA e antígenos alvo (S e RBD, uma porção da proteína spike que se liga ao receptor), e são formuladas usando o sistema de entrega LNP. Dois candidatos incluem mRNA modificado com nucleosídeo (modRNA), um inclui um mRNA contendo uridina (URNA) e o quarto candidato a vacina é baseado em saRNA.

A Biocad (São Petersburgo, Rússia) está desenvolvendo uma vacina de mRNA contra SARS-COV-2 com base na experiência anterior com vacinas contra o câncer baseadas em mRNA. A vacina candidata de mRNA Covid-19 codesenvolvida pelo Centro Chinês para Controle e Prevenção de Doenças (Pequim, China), Escola de Medicina da Universidade de Tongji (Xangai, China) e Stermirna Therapeutics (Xangai, China) é baseada na síntese de mRNA de Stermirna e plataforma de entrega de nano lipopolyplex. A Fudan University (Fudan, China), em cooperação com a Shanghai JiaoTong University (Shanghai, China) e a RNACure Biopharma (Shanghai, China), está buscando duas estratégias diferentes para desenvolver vacinas de mRNA contra Covid-19. A primeira estratégia inclui um mRNA que codifica o RBD da proteína S para induzir nAbs, enquanto a segunda estratégia inclui um mRNA que instrui o hospedeiro a produzir VLPs, partículas virais (Frederiksen et al. 2020).

O Imperial College London (Londres, Reino Unido) está desenvolvendo uma vacina de mRNA COVID-19 com base em trabalho anterior com RNA de auto-amplificação encapsulado por nanopartículas lipídicas (LNP), que já foi mostrado para induzir anticorpos contra o envelope gp140 do HIV-1 (Blakney et al. 2019; Blakney et al. 2018). A Arcturus Therapeutics (San Diego, CA, EUA), em colaboração com a Duke National University of Singapore (Cingapura), está desenvolvendo uma vacina candidata usando sua plataforma de tecnologia STARR TM (RNA de auto-transcrição e replicação) que combina RNA de autoreplicação com a entrega de nanopartículas em uma única solução para a expressão in situ das proteínas SARS-CoV-2 que induzem uma resposta imune antiviral (Ramaswamy et al., 2017).

A eTheRNA Immunotherapies (Niel, Bélgica) está desenvolvendo uma nova vacina usando a plataforma de tecnologia proprietária TriMix, que compreende três diferentes mRNAs que codificam proteínas (caTLR4, CD40L e CD70) que estimulam as células dendríticas a ativar CD4+ e respostas de células $\mathrm{T}+\mathrm{CD} 8$, e foi mostrado para induzir respostas imunogênicas em estudos pré-clínicos e clínicos de uma vacina de melanoma baseada em mRNA. Ademais, a Sanofi Pasteur e Translate Bio (Lexington, MA, EUA) estão colaborando para desenvolver uma nova vacina de mRNA baseada na plataforma terapêutica de mRNA proprietária da Translate Bio. Esta plataforma inclui o projeto das sequências de mRNA desejadas e, em seguida, empacotá-las em sistemas de entrega e foi demonstrado que induz anticorpos contra tumores positivos para o receptor 2 do fator de crescimento epidérmico humano em camundongos humanizados (Rybakova et al., 2019).

O Centro Nacional de Biotecnología (Madrid, Espanha) está desenvolvendo uma vacina candidata de mRNA Covid19 com base no vetor de poxvírus altamente atenuado que expressa a proteína S, que foi previamente testado como um vetor para vacinas candidatas contra os vírus Zika e Ebola (Perez et al., 2018; Frias et al., 2018). A Daiichi Sankyo (Tóquio, Japão) desenvolveu uma vacina de mRNA que codifica a proteína $\mathrm{S}$ usando sua nova tecnologia de entrega de ácido nucleico baseada em LNPs, e os efeitos protetores da vacina serão verificados em modelos animais em parceria com a Universidade de Tóquio. (Marzi et al., 2015).

O desenvolvimento da vacina para Covid-19 é um processo altamente complexo que envolve estudos genômicos virais, identificação do alvo da vacina, projeto, fabricação, armazenamento e distribuição da vacina, estudos pré-clínicos e 
clínicos de segurança e eficácia. Os altos níveis de esforços e colaboração global nesta escala não têm precedentes. A Organização Mundial da Saúde (OMS) documentou 160 vacinas candidatas Covid-19 diferentes em 13 de julho de 2020, com 26 atualmente em avaliação clínica e 137 vacinas em avaliação pré-clínica. Os esforços da vacina COVID-19 marcam o primeiro uso de vacinas do tipo mRNA já avaliadas. (Haq et al., 2020).

As vacinas de RNA mensageiro têm demonstrado, em geral, um excelente perfil de segurança e com boas respostas imunes celular e humoral. Tem a vantagem de serem produzidas em maior escala, por se tratar de produtos sintéticos, e a desvantagem de serem produtos que requerem conservação em congelamento (Lima et al., 2021). Várias plataformas estão em desenvolvimento. Entre aqueles com maior potencial de velocidade estão as plataformas baseadas em DNA e RNA, seguidas por aquelas para o desenvolvimento de vacinas de subunidades recombinantes. As vacinas de RNA e DNA podem ser feitas rapidamente porque não requerem cultura ou fermentação (Lurie, et al. 2020).

\section{Conclusão}

Nas células humanas, têm-se o DNA, que armazena as informações genéticas, o RNA, molécula que leva instruções para a síntese de proteínas e para outras funções biológicas, e os ribossomos, que são estruturas do citoplasma da célula que efetivamente produzem as proteínas com as instruções trazidas pelo mRNA. Assim, ao invés de injetar o vírus atenuado ou inativo ao corpo humano, a vacina de RNA ensina as células humanas a produzirem uma proteína específica do próprio vírus, o antígeno viral, que vai estimular a resposta imunológica do organismo contra o vírus. Ou seja, elas atuam introduzindo nas células do organismo a sequência de mRNA, que contém a receita para que essas células produzam uma proteína específica do vírus. Essa imunidade, representada pelas proteínas produzidas pelos plasmócitos (linfócitos B), que são as células de defesa, e linfócitos T, dá ao organismo a capacidade de se defender quando em contato com o vírus.

A vacina de mRNA, que contém o RNA codificador de uma proteína da superfície do vírus, corrobora a produção, pelas células humanas, da proteína spike, através da receita do RNA, e, assim, o corpo aprende como se defender do vírus, quando o contato acontece. Este é apenas o início de uma grande revolução tecnológica para a produção de vacinas que poderão, no futuro, combater diversos outros vírus usando essa tecnologia com segmentos de mRNA diferentes, propiciando o desenvolvimento de tratamentos para várias doenças através do mesmo princípio de ação.

\section{Referências}

Alwis, R., Chen, S., Gan, E.S. \& Ooi, E.E. (2020). Impact of immune enhancement on Covid-19 polyclonal hyperimmuneglobulin therapy and vaccine development. EBioMedicine. 55 (102768), 1-7.

Amanat, F. \& Krammer, F. (2020). SARS-CoV-2 Vaccines: Status Report. Immunity. 52 (4): 583-589.

Avorn, J. \& Kesselheim, A. (2020). Regulatory Decision-making on COVID-19 Vaccines During a Public Health Emergency. JAMA. 324 (13), $1284-1285$.

Barreto, M.C. \& Vasconcelos, H. C. (2021). Como as nanopartículas nos defendem da COVID-19: entregas da vacina de RNAm diretamente às células. Açoriano Oriental, Açores Magazine, UAciência, 10-11.

Blakney, A. K., Yilmaz, G., McKay, P. F., Becer, C. R. \& Shattock, R. J. (2018). Um tamanho não serve para todos: o efeito do comprimento da cadeia e densidade de carga de copolímeros à base de poli (etileno imina) na entrega de poliplexos de pDNA, mRNA e RepRNA. Biomacromoléculas. 19 (1), 28702879 .

Blakney, A.K., McKay, P.F., Yus, B.I., Aldon, Y. \& Shattock, R.J. (2019). De dentro para fora: otimização de formulações de nanopartículas lipídicas para complexação externa e entrega in vivo de saRNA. Gene Ther. 26 (1), 363-372.

Caddy, S. (2020). Developing a vaccine for covid-19. BMJ. 369 (1790), 1-2.

Dearlove, B., Lewitus E., Bai H., Li, Y., Reeves, D.B. \& Joyce, M.G. (2020). A SARS-CoV-2 vaccine candidate would likely match all currently circulating strains. Evolutionary Biology. 117 (38), 23652-23662.

Espeseth, A.S., Cejas, P.J., Citron, M.P., Wang, D., DiStefano, D.J. \& Callahan, C. (2020). As vacinas à base de nanopartículas lipídicas / mRNA modificadas que expressam variantes da proteína $\mathrm{F}$ do vírus sincicial respiratório são imunogênicas e protetoras em modelos de roedores de infecção por RSV. NPJ Vaccines. 5 (16). 
Research, Society and Development, v. 10, n. 10, e246101018818, 2021

(CC BY 4.0) | ISSN 2525-3409 | DOI: http://dx.doi.org/10.33448/rsd-v10i10.18818

Frederiksen, L.S.F., Zhang, Y., Foged, C. \& Thakur, A. (2020). The Long Road Toward COVID-19 HerdImmunity: Vaccine Platform Technologies and Mass Immunization Strategies. Front Immunol. 11 (1817), 1-26. https://doi.org/10.3389/fimmu.2020.01817.

Frias, L. A., Gomez-Medina, S., Sanchez-Sampedro, L., Ljungberg, K., Ustav, M. \& Liljestrom, P. (2018). Imunogenicidade e eficácia distintas de candidatos a vacinas baseadas em poxvírus contra o vírus Ebola que expressam proteínas GP e VP40. J Virol. 92 (1), 363-368.

Haq, E.U., Yu, J. \& Guo, J. (2020). Frontiers in the COVID-19 vaccines development. Exp Hematol Oncol., 9 (24), 1-24. https://doi.org/10.1186/s40164-02000180-4

Jackson, L. A., Anderson, E.J., Rouphael, N.G., Roberts, P.C., Makhene, M., Coler, R.N. \& McCullough, M. P. (2020). An mRNA Vaccine against SARSCoV-2: Preliminary Report. N Engl J Med. 383 (1), 1920-1931.

Kauffman, K. J., Dorkin, J. R., Yang, J. H., Heartlein, M. W., DeRosa, F. \& Mir, F. F. (2015). Otimização de formulações de nanopartículas lipídicas para entrega de mRNA in vivo com projetos fatoriais fracionários e de triagem definitiva. Nano Lett. 15 (1), 7300-7306.

Lima, E.J.F., Almeida, A. M. \& Kfouri, R. A. (2021). Vacinas para Covid-19: o estado da arte. Rev. Bras. Saúde Mater. Infant., 21 (1), $521-528$. http://dx.doi.org/10.1590/1806-9304202100S100002

Lurie, N., Saville, M., Hatchett, R. \& Halton J. (2020). Desenvolvimento de vacinas para Covid-19 em velocidade pandêmica. N Engl J Med. 382 (21): 1969 1973.

Marzi, A., Halfmann, P., Hill-Batorski, L., Feldmann, F., Shupert, W. L. \& Neumann, G. (2015). Vacinas: Uma vacina contra o vírus ebola é protetora em primatas não humanos. Science. 348 (1), 439-442.

Mukherjee, R. (2020). Global efforts on vaccines for COVID-19: Since, sooner or later, we all will catch the coronavirus. J Biosci. 45 (68), 1-16.

Perez, P. M.Q.M, Frias, L. A., Oya, N. J., Blazquez, A.B. \& Escribano-Romero, E. (2018). Uma vacina baseada em um vetor de Ancara do vírus vaccinia modificado que expressa as proteínas estruturais do vírus zika controla a replicação do vírus zika em camundongos. Sci Rep. 8 (1), 17385.

Ramaswamy, S., Tonnu, N., Tachikawa, K., Limphong, P., Vega, J. B. \& Karmali, P. P. (2017). Entrega sistêmica de RNA mensageiro do fator IX para terapia de reposição de proteínas. Proc Natl Acad Sci USA. 114 (1), 1941-1950.

Rybakova, Y., Kowalski, P. S., Huang, Y., Gonzalez, J. T., Heartlein, M.W. \& DeRosa, F. (2019). Entrega de mRNA para expressão terapêutica de anticorpo anti-HER2 in vivo. Mol Ther. 27 (1), 1415-1423.

Stadler, C.R., Bahr-Mahmud, H., Celik, L., Hebich, B., Roth, A.S. \& Roth R. P. (2017). Eliminação de grandes tumores em camundongos por anticorpos biespecíficos codificados por mRNA. Nat Med. 23 (1), 815-817. 